\title{
Barriers to Smoking Cessation and Characteristics of Pregnant Smokers in Greece
}

Athina DIAMANTI a , Aikaterini GALIATSATOU ${ }^{a}$, Antigoni SARANTAKI ${ }^{\mathrm{a}}$, Paraskevi KATSAOUNOU ${ }^{\mathrm{b}, \mathrm{c}}$, Dimitra VARNAKIOTI ${ }^{\mathrm{a}}$, Aikaterini LYKERIDOU ${ }^{\mathrm{a}}$

aDepartment of Midwifery, University of West Attica, Egaleo, Greece

bSchool of Medicine, National and Kapodistrian University of Athens, Athens, Greece

'First ICU, Evangelismos Hospital, Athens, Greece

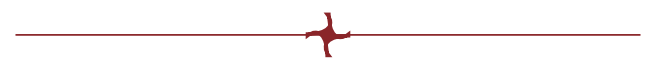

\footnotetext{
ABSTRACT

Objectives: Nicotine addiction and the inability of a large part of pregnant smokers to quit is one of the main preventable causes of morbidity and mortality during the perinatal period. The aim of this study is to investigate nicotine dependence and overall smoking habits of pregnant smokers and to possibly correlate them with smokers' social and demographic characteristics.

Materials and methods: One hundred and fourteen pregnant smokers answered an electronic questionnaire consisting of 59 questions, which was divided into six sections. The questionnaires were filled out by participants from many regions of Greece and Cyprus.

Results: Before their pregnancy, women smoked 19 cigarettes per day on average, while during their pregnancy they dropped to eight cigarettes per day; $65.8 \%$ of respondents stated that their husband smoked, while $58.8 \%$ answered that they had been exposed to secondhand smoke; $13.2 \%$ of pregnant smokers stated that they had had depression at some point in their lives and 14.9\% reported having undergone domestic violence; $55.3 \%$ of respondents acknowledged that smoking was responsible for a variety of adverse effects to the fetus; and $97.4 \%$ of pregnant women did not follow a smoking cessation counseling program, compared to just $2.6 \%$ who did.

Conclusions: The pregnant smokers in our study did not have appropriate information about the available smoking cessation services, which were not generally considered to be useful for them, and consequently they did not utilize cessation assistance. The resistance towards quitting smoking, which was observed in the sample, may also be attributed to the lack of specialized smoking cessation services in maternity hospitals in Greece.

Keywords: maternal smoking in pregnancy, smoking, tobacco, second hand smoke, smoking cessation, pregnancy complications, nicotine addiction.
}

\footnotetext{
Address for correspondence:

Dr. Athina Diamanti

Midwifery Department, University of West Attica, Egaleo, Greece

Land line: +302130239669

ORCID: https://orcid.org/0000-0002-5963-3318

Email:adiamanti@uniwa.gr
} 


\section{INTRODUCTION}

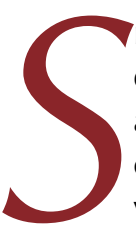
moking related conditions are the leading cause of morbidity and mortality among the female population. The percentage of women who smoke worldwide ranges from $17 \%-22 \%$ (1). In Greece, recent studies show that this percentage appears to reach $37.7 \%$ in women aged between 18 and 34, which also happens to be their main reproductive period (2). According to the World Health Organization (1), the percentage of women who smoke worldwide is constantly increasing. This increase is observed mainly in economically weak countries and also encompasses an increase in the use of other tobacco products such as electronic cigarettes, hookah, etc. (1). Although pregnancy is a period with good rates of successful smoking cessation, compared to other periods in a woman's life, and despite the pregnant women strong motivation to quit smoking during this particular period, the prevalence of those who continue to smoke during pregnancy is considerably high, especially in Greece $(3,4)$. The presence of certain aggravating factors and obstacles which prevent them from quitting smoking during pregnancy is therefore evident.

Both first- and second-hand smoke exposure during pregnancy cause a plethora of unfavorable complications not only to the future mothers but also to the embryo. Outcomes of these complications will continue to affect the infant later in life during childhood and even adulthood (5-12).

Being able to detect the social, financial, demographic, stress inducing, psychological and biological risk factors associated with failure to quit smoking during pregnancy early enough will definitely contribute to the reduction or prevention of unfavorable outcomes that smoking has on pregnancy itself as well as on the health of the embryo and that of the infant-to-be.

The aim of the study was to detect the factors which affect women's smoking status and especially those that prevent pregnant women from quitting smoking.

\section{MATERIAL AND METHODS}

\section{tudy design and population}

This is a cross-sectional study, electronically conducted between September 2019 and December 2019, with female participants from various places of Greece and Cyprus. Despite the relatively small size of our sample, it consisted of individuals with various educational, social and economic levels, therefore qualifying as representative sample.

\section{Research questionnaire}

The research questionnaire consisted of 59 questions and was divided into six sections. Various types of questions were used such as dichotomous, categorical, short answer, Likert type and multiple choice. The questionnaire had the following structure:

- the first section explored the smoking status and included 19 questions;

- the second section explored nicotine addiction and included 11 questions;

- the third section explored smoking cessation efforts and included six questions;

- the fourth section explored health effects and included 11 questions;

- the fifth section explored the interventions for smoking cessation and included five questions;

- the sixth section explored demographic characteristics and included seven questions.

All study procedures were performed in accordance with the ethical standards of the university institutional research committee as well as the 1964 Helsinki Declaration and its later amendments. No personally identifiable information was collected and all electronic forms were anonymous. The questionnaire used in the study is a synthesis of the questionnaire of Fagerstorm \& Schneider (1989) (13) concerning smoking dependence and some questions regarding subjects' sociodemographic characteristics. The questionnaire was licensed by (14).

The survey link was primarily shared via email, Facebook and Instagram. It was also promoted through pregnancy-specific professional communities for distribution over their networks of pregnant women.

\section{Statistical analysis}

It was performed in the statistical program IBM SPSS 24 in parallel with the use of Microsoft Office Excel 2016. Ordinal variables and quantitative variables were presented with mean values and standard deviations, and categorical variables with frequencies and percentages. 
Mann Whitney or Kruskal Wallis non-parametric control was used to check the dependence of a quantitative variable of quality two or three and more categories, respectively, in the cases where there were small samples $(\mathrm{n}<30)$ or samples which did not follow the normal distribution. The initial hypothesis of the test was that the $k$ samples $(k \geq 2)$ were from the same population and the alternative hypothesis was that they were from different populations. Independent samples t-test was used to check the mean values of two samples following the normal distribution. The initial hypothesis of the test was that the mean values were equal, while the alternative hypothesis was that they differed. The $X^{2}$ test of independence was used to control the dependence of quality variables. The initial hypothesis of control was that the variables were independent, while the alternative hypothesis was that they are dependent. The significance level of the tests was set to $5 \%$, with the initial hypothesis being accepted for $p$-value $\geq 0.05$ and rejected when $p$-value $<0.05$ (Kolyva-Macheira, Bora-Senta \& Bratsas, 2017).

\section{Data reliability}

Data reliability was calculated using the Cronbach alpha coefficient, where values greater than 0.7 were considered acceptable (15). The survey questionnaire had only two factors which resulted from Likert type questions and the reliability was greater than 0.790 .

\section{RESULTS}

$\mathrm{O}$ ne hundred and fourteen pregnant smokers aged 19-42 years consented to take part in the present study; $41.2 \%(\mathrm{~N}=47)$ of participants were aged between 25 and 30 years, 32.5\% $(\mathrm{N}=37)$ between 31 and 36, 15.8\% ( $\mathrm{N}=18)$ between 37 to 42 and the remaining $10.5 \%(\mathrm{~N}=12)$ between 19 and 24 years. Of all pregnant women, $56.7 \%$ had an expected pregnancy and $97,4 \%(\mathrm{~N}=111)$ of them had a desired pregnancy. Regarding the gestational age, $30.7 \%$ of all pregnant women $(\mathrm{N}=35)$ reported being at 24 to 33 weeks of gestation, $28.9 \%(\mathrm{~N}=33)$ at 14 to $23,24.6 \%(\mathrm{~N}=28)$ at 4 to 13 and $15.8 \%(\mathrm{~N}=18)$ at 34 to 40 weeks of gestation. The sociodemographic characteristics of the sample are presented in Table 1.
TAB BE 1. Socio-demographic data

\begin{tabular}{|c|c|c|c|}
\hline Characteristics & Age group (years) & $N=114^{*}$ & $\mathbf{F} \%$ ** \\
\hline \multirow{4}{*}{ Age (years) } & $19-24$ & 12 & 10.5 \\
\hline & $25-30$ & 47 & 41.2 \\
\hline & $31-36$ & 37 & 32.5 \\
\hline & $37-42$ & 18 & 15.8 \\
\hline \multirow{4}{*}{ Nationality } & Greek & 104 & 92 \\
\hline & Albanian & 4 & 3.5 \\
\hline & Bulgarian & 2 & 1.8 \\
\hline & Cypriot & 3 & 2.7 \\
\hline \multirow{4}{*}{ Gestational age (weeks) } & $4-13$ & 28 & 24.6 \\
\hline & $14-23$ & 33 & 28.9 \\
\hline & $24-33$ & 35 & 30.7 \\
\hline & $34-40$ & 18 & 15.8 \\
\hline \multirow{5}{*}{ Marital status } & Single & 7 & 6.1 \\
\hline & Married & 95 & 83.3 \\
\hline & Divorced & 1 & 0.9 \\
\hline & Separated & 1 & 0.9 \\
\hline & Cohabitation agreement & 10 & 8.8 \\
\hline \multirow{6}{*}{ Work status } & Public sector & 11 & 9.6 \\
\hline & Private sector & 44 & 38.6 \\
\hline & Self-employed & 15 & 13.2 \\
\hline & Part time & 7 & 6.1 \\
\hline & Unemployed & 16 & 14.0 \\
\hline & Housewife & 21 & 18.4 \\
\hline \multirow{6}{*}{ Educational level } & Primary school & 11 & 9.6 \\
\hline & Middle school - High school & 26 & 22.8 \\
\hline & Vocational training & 24 & 21.1 \\
\hline & University / College & 41 & 36.0 \\
\hline & MSc & 9 & 7.9 \\
\hline & $\mathrm{PhD}$ & 3 & 2.6 \\
\hline Yearly income $(€)$ & $\begin{array}{l}0-7000 \\
7001-10000 \\
10001-15000 \\
15001-20000 \\
\text { over } 20000\end{array}$ & $\begin{array}{l}52 \\
20 \\
23 \\
13 \\
6\end{array}$ & $\begin{array}{l}45.6 \\
17.5 \\
20.2 \\
11.4 \\
5.3\end{array}$ \\
\hline
\end{tabular}

${ }^{*} \mathrm{~N}=$ sample

$* * \mathrm{~F} \%=$ frequency $\%$

Interestingly, in Table 1 it can be seen that the vast majority of participants report an annual income of less than 15,000 euros. Additionally, Table 2 shows important details about the smoking history of pregnant women who participated in the survey (e.g., how many cigarettes they smoked and for how long, etc), their exposure to second hand smoke, abnormalities in their previous pregnancies (e.g., premature births, etc.) and the smoking status of their partners.

Of all participants, 32.5\% ( $\mathrm{N}=37)$ reported they had given birth prematurely in a previous pregnancy. Additionally, of all pregnant smokers, 


\begin{tabular}{|l|l|l|}
\hline Questions & Mean & SD $^{*}$ \\
\hline How long have you been smoking cigarettes? (years) & 13.5 & 5.38 \\
\hline How many cigarettes did you smoke before pregnancy? (per day) & 19.1 & 8.06 \\
\hline How many cigarettes do you smoke? (per day) & 7.94 & 6.92 \\
\hline Which month of your pregnancy are you at? & 5.52 & 2.35 \\
\hline $\begin{array}{l}\text { How many times have you been pregnant? (including miscarriages } \\
\text { and stillbirths) }\end{array}$ & 2.07 & 1.34 \\
\hline How many children do you have? & 1.47 & 0.93 \\
\hline $\begin{array}{l}\text { If you have given birth prematurely, mention the neonates' body } \\
\text { weight at birth. }\end{array}$ & 2.06 & 0.19 \\
\hline How many times have you given birth prematurely? & 1.11 & 0.33 \\
\hline What was the weight of your previous child in grams? & 3152 & 451 \\
\hline $\begin{array}{l}\text { If your partner smokes, how many cigarettes does he or she smoke } \\
\text { (per day)? }\end{array}$ & 20.2 & 9.95 \\
\hline $\begin{array}{l}\text { Approximately how many cigarettes does your partner smoke at } \\
\text { home in your presence (exposure to second hand smoking)? }\end{array}$ & 10.4 & 8.5 \\
\hline
\end{tabular}

*SD: standard deviation
TABLE 2. Past and present smoking status, abnormalities in previous pregnancies and other data
28.9\% $(\mathrm{N}=33)$ responded that some of their previous pregnancies had been miscarriages and $2.63 \%(\mathrm{~N}=3)$ had vaginal bleeding during the current pregnancy. In our sample, it seemed that another disadvantage of smoking during pregnancy was the lack of exercise, as $70 \%(\mathrm{~N}=7)$ of pregnant smokers stated they have actively avoided exercising because they smoke.

Furthermore, $36.0 \% \quad(\mathrm{~N}=41)$ of pregnant smokers reported being exposed to tobacco smoke in their workplace and 58.8\% $(\mathrm{N}=67)$ to secondhand smoke in public places; $65.8 \%$ $(\mathrm{N}=75)$ of the sample mentioned their partners smoked and $94.7 \% \quad(\mathrm{~N}=108)$ of pregnant smokers stated they had friends who were smokers.

Of the entire sample, $13.2 \%(\mathrm{~N}=15)$ had an old or recent history of depression and $14.9 \%$ $(\mathrm{N}=17)$ an old or recent history of domestic violence. In addition, the majority of participants (53.5\% ( $\mathrm{N}=61)$ were highly addicted to nicotine. Table 3 shows that $38.6 \%(\mathrm{~N}=44)$ of pregnant smokers reported smoking within six to 30 minutes after waking up, and $14.9 \%(\mathrm{~N}=17)$ within five minutes, which is an indicator of higher levels of nicotine addiction. Also, Table 3 summarizes more data on participants' smoking habits.

A very interesting result of our study was the observation that $97.4 \%(\mathrm{~N}=111)$ of pregnant smokers did not follow counseling programs for smoking cessation neither in the past nor in the present pregnancy, while only $2.6 \%(\mathrm{~N}=3)$ re- ceived some help. Only $10.5 \%(\mathrm{~N}=2)$ of pregnant smokers reported having managed to quit smoking in the past without help. Despite the difficulties for smoking cessation reported by pregnant smokers, it is very encouraging nevertheless that $49.6 \%(\mathrm{~N}=56)$ of smokers stated they were actually considering the possibility of quitting smoking. A larger percentage (about $60 \%$ of respondents) positively regard the implementation of the anti-smoking law (new legislation prohibiting smoking in public places).

Only $2.6 \%(\mathrm{~N}=3)$ of pregnant smokers answered that the main source of information about the negative consequences of smoking was the obstetrician or the midwife, while the vast majority of them received information from the media, the Internet, their family and friends.

In Table 3, important details about pregnant smokers' smoking habits can be seen.

There was also a statistically significant difference between the number of cigarettes smoked by pregnant women daily, the number of smoking cessation attempts and the duration (in days) of smoking cessation achieved compared to their educational level.

Table 4 summarizes the results of the Kruskal Wallis tests of the quantitative-ordinal variables of our study which refer to the smoking status in relation to educational level. A statistically significant dependence was found in the variables "How many cigarettes do you smoke a day?" [H $(2)=11.919, p=0.003]$, "How many times have you tried to quit smoking?" [H (2)=7.280, 


\begin{tabular}{|c|c|c|c|}
\hline Questions & Answers & $\mathbf{N}^{*}$ & $\mathbf{F} \%{ }^{* *}$ \\
\hline \multirow{4}{*}{$\begin{array}{l}\text { How soon after you wake up do you smoke your first } \\
\text { cigarette? }\end{array}$} & After one hour & 28 & 24.6 \\
\hline & Within 30 to 60 minutes & 25 & 21.9 \\
\hline & Within six to 30 minutes & 44 & 38.6 \\
\hline & Within five minutes & 17 & 14.9 \\
\hline \multirow{2}{*}{$\begin{array}{l}\text { Do you find it difficult to refrain from smoking in places } \\
\text { where it is forbidden, e.g., in church, at the library, in the } \\
\text { cinema? }\end{array}$} & No & 62 & 54.4 \\
\hline & Yes & 52 & 45.6 \\
\hline \multirow{2}{*}{ Which cigarette would you hate most to give up? } & Any other & 38 & 33.3 \\
\hline & The first in the morning & 76 & 66.7 \\
\hline \multirow{4}{*}{ How many cigarettes per day do you smoke? } & 10 or less & 86 & 75.4 \\
\hline & 11 to 20 & 16 & 14.0 \\
\hline & 21 to 30 & 9 & 7.9 \\
\hline & 31 or more & 3 & 2.6 \\
\hline \multirow{2}{*}{$\begin{array}{l}\text { Do you smoke more frequently during the first hours after } \\
\text { waking up compared to the rest of the day? }\end{array}$} & No & 50 & 43.9 \\
\hline & Yes & 64 & 56.1 \\
\hline \multirow{2}{*}{$\begin{array}{l}\text { Do you smoke even when an illness forces you to stay in } \\
\text { bed? }\end{array}$} & No & 56 & 49.1 \\
\hline & Yes & 58 & 50.9 \\
\hline \multirow{2}{*}{ Are there people in your friendly environment who smoke? } & No & 6 & 5.3 \\
\hline & Yes & 108 & 94.7 \\
\hline \multirow{5}{*}{ How do you feel when you smoke? } & Enjoyment /joyful & 27 & 23.9 \\
\hline & Release/liberation/freedom & 4 & 3.5 \\
\hline & Relief & 12 & 10.6 \\
\hline & Relaxation & 46 & 40.7 \\
\hline & Calmness/peacefulness & 24 & 21.2 \\
\hline \multirow{6}{*}{ Why do you keep smoking during pregnancy? } & $\begin{array}{l}\text { To calm down from emotional } \\
\text { stress }\end{array}$ & 51 & 45.1 \\
\hline & For pleasure & 12 & 10.6 \\
\hline & $\begin{array}{l}\text { Because it banishes loneliness } \\
\text { and fills my time }\end{array}$ & 6 & 5.3 \\
\hline & $\begin{array}{l}\text { Because it increases energy } \\
\text { and helps at work }\end{array}$ & 4 & 3.5 \\
\hline & By habit & 36 & 31.9 \\
\hline & $\begin{array}{l}\text { Other (constipation, } \\
\text { deprivation, inability to relax) }\end{array}$ & 4 & 3.5 \\
\hline \multirow{2}{*}{$\begin{array}{l}\text { Have you followed smoking cessation counseling } \\
\text { programs? }\end{array}$} & Yes & 3 & 2.6 \\
\hline & No & 111 & 97.4 \\
\hline \multirow{3}{*}{ Have you used medication to quit smoking in the past? } & No & 24 & 57.1 \\
\hline & Nicotine replacement therapy & 16 & 38.1 \\
\hline & Bupropion & 2 & 4.8 \\
\hline \multirow{3}{*}{ Who informed you about smoking cessation interventions? } & Doctor & 38 & 55.1 \\
\hline & Midwife & 6 & 8.7 \\
\hline & Other & 25 & 36.2 \\
\hline \multirow{2}{*}{$\begin{array}{l}\text { Did you manage to quit smoking with some of those } \\
\text { interventions? }\end{array}$} & Yes & 5 & 6.6 \\
\hline & No & 71 & 93.4 \\
\hline \multirow{3}{*}{$\begin{array}{l}\text { With what intervention did you finally manage to quit } \\
\text { smoking? }\end{array}$} & I did not manage to quit & 13 & 68.4 \\
\hline & $\begin{array}{l}\text { Without any help (I managed } \\
\text { on my own) }\end{array}$ & 2 & 10.5 \\
\hline & $\begin{array}{l}\text { Other (e-cigarette, counseling } \\
\text { from my doctor) }\end{array}$ & 4 & 21.1 \\
\hline
\end{tabular}

TAB LE 3. Fagerstrom test and smoking habits of pregnant smokers

*N=sample

$\mathrm{p}=0.026]$ and "For how long (days) have you managed to quit smoking?" $[\mathrm{H} \quad(2)=6.066$, $\mathrm{p}=0.048]$.
Table 5 presents the results of the $X^{2}$ tests of the qualitative-dichotomous variables of our study which refer to the smoking behavior in 
TAB LE 4. Results of Kruskal Wallis tests regarding participants' level of education and smoking status

\begin{tabular}{|l|l|l|}
\hline Quantitative-operative variables & Kruskal Wallis, H(2)-test & p-value \\
\hline For how many years have you smoked? & 0,004 & 0.998 \\
\hline How many cigarettes did you smoke before pregnancy per day? & 0,052 & 0.974 \\
\hline How many cigarettes do you smoke per day now? & 2.873 & 0.238 \\
\hline How soon after you wake up do you smoke your first cigarette? & 3.232 & 0.199 \\
\hline How many cigarettes do you smoke per day? & 11.919 & $\mathbf{0 . 0 0 3}$ \\
\hline Nicotine addiction & 1,102 & 0.576 \\
\hline Opinion on the measures of banning smoking in public places & 2.401 & 0.301 \\
\hline How many times have you tried to quit smoking? & 7.280 & $\mathbf{0 . 0 2 6}$ \\
\hline For how long (days) have you managed to quit smoking? & 6.066 & $\mathbf{0 . 0 4 8}$ \\
\hline
\end{tabular}

TABLE 5. Results of $X^{2}$ tests in relation to annual income

\begin{tabular}{|l|l|l|}
\hline Qualitative-dichotomous variables & $\mathbf{X}^{\mathbf{2}^{*}}$ & $\mathbf{p}$-value \\
\hline Are you exposed to secondhand smoke at work? & 4.068 & 0.254 \\
\hline Are you exposed to secondhand smoke in public places? & 1.657 & 0.647 \\
\hline Is it difficult for you not to smoke in places where smoking is prohibited? & 0.261 & 0.967 \\
\hline Do you smoke even when an illness forces you to stay in bed? & 0.686 & 0.876 \\
\hline Have you tried to quit smoking? & 1.064 & 0.786 \\
\hline Do you think you are addicted to nicotine / cigarettes? & 0.512 & 0.916 \\
\hline $\begin{array}{l}\text { Have you ever felt that your smoking habit has isolated you from your social } \\
\text { environment? }\end{array}$ & 6.383 & 0.094 \\
\hline Do you think that smoking has enhanced your sociability? & 2.875 & 0.411 \\
\hline have you followed smoking cessation counseling programs? & 5.886 & 0.117 \\
\hline Have you used prescribed medication to quit smoking in the past? & 8.873 & $\mathbf{0 . 0 3 1}$ \\
\hline Did you manage to quit smoking with smoking cessation interventions? & 2.250 & 0.522 \\
\hline
\end{tabular}

* $\mathrm{X}^{2}$ : Pearson's chi-squared test

relation to annual income, where a statistically significant dependence was identified in the variable "Have you used drugs to quit smoking in the past?" [ $\left.X^{2}(3)=8.873, p=0.031\right]$.

\section{DISCUSSION}

The majority of participants were aged between 25 and 36 years $[41.2 \%(\mathrm{~N}=47)$ between 25 and 30 years and $32.5 \%(\mathrm{~N}=37)$ between 31 and 36 years], and data were consistent with previously reported maternal age patterns in Greece $(3,4)$.

Almost half (45.6\%) of pregnant smokers stated that they had an annual income of less than 7000 euros. As in previous studies, a statistically significant difference of annual income and smoking status during pregnancy has been reported. We have also found a statistically significant difference between different annual incomes and smoking status of pregnant women; this finding was in line with an earlier study in which pregnant women who quitted smoking spontaneously had higher annual incomes (16).

Another important finding that is in agreement with previous research in Greece (3) as well as other international studies (16) is the statistically significant difference in the level of education of participants and their smoking status and behavior. In our study, half of pregnant smokers did not have higher education, while there was a statistically significant difference in many variables related to participants' smoking behavior (such as smoking cessation efforts) and their educational level. In the Linares Scott 2009 study, pregnant women who quitted smoking spontaneously had a higher level of education and smoked a smaller number of cigarettes per day before pregnancy (16).

Our study has found that the vast majority (97.4\% / N=111) of pregnant smokers did not receive help from someone specialized in smoking cessation. Although pregnant smokers made unsuccessful smoking cessation efforts in the past 
and some of them were aware of the adverse effects of smoking in pregnancy, it was noted that perinatal care in Greece was not offering either nicotine replacement therapy or smoking cessation counseling; consequently, very few pregnant smokers end up receiving such services. This has also been observed in a previous study that was conducted in Greece in 2019. In particular, in the survey of Diamanti et al, only $5.4 \%$ of pregnant smokers received help from a healthcare professional trained in smoking cessation (3). Unfortunately, the percentage of pregnant smokers who used to visit smoking cessation clinics or seek help from a healthcare professional specialized in smoking cessation has not increased, although many studies were showing high success rates of these programs and services (17). Additionally, the percentage of high nicotine addiction was found to be quite high in our sample (55\%). Therefore, the significantly increased metabolism of nicotine in pregnancy could explain how important is to prescribe the proper dose and the proper combination of medication used in nicotine replacement therapy in order to achieve positive results (18).

As far as preterm delivery is concerned, $32.5 \%(\mathrm{~N}=37)$ of participants reported they gave birth prematurely in a previous pregnancy. According to previous studies, the overall rate of preterm delivery is approximately $4.3 \%$. Smokers had a $40 \%$ higher risk of preterm delivery than non-smokers and there was a dose-dependent relationship between smoking and risk of preterm birth (19). Additionally, 28.9\% ( $\mathrm{N}=33)$ of pregnant smokers reported that some of their previous pregnancies ended in miscarriages and $2.63 \%(\mathrm{~N}=3)$ of pregnant smokers reported having vaginal bleeding during the current pregnancy. These findings are consistent with those provided by earlier studies reporting smokingrelated complications during pregnancy $(20,21)$.

Regarding our sample's exposure to tobacco secondhand smoke, $36.0 \%(\mathrm{~N}=41)$ of pregnant smokers reported they were exposed in the workplace and $58.8 \%(\mathrm{~N}=67)$ in public places. Of all respondents, $65.8 \%(\mathrm{~N}=75)$ stated that their partners smoked too, while $94.7 \%(\mathrm{~N}=108)$ of pregnant smokers had friends who were also smokers. Thus, the partner, friends, and family of a pregnant smoker can generally support her efforts to quit smoking, and this often decisive contribution has been also observed in the inter- national literature (5). In the case of pregnant smokers, failure to receive support from partner, family and social environment is a major factor which undermines the success of quit attempts during pregnancy $(5,9,22)$. Previous studies have also reported that women who did not stop smoking during pregnancy typically had either family members or partners who smoked, or lived with relatives who were smoking $(23,24)$. Consequently, partners seem to play an important role in influencing women's smoking behavior in the perinatal period, and receiving support can significantly facilitate their efforts to quit. It is therefore evident that a partner who continues to use tobacco throughout a woman's pregnancy is a significant predictor of the current smoking status of the pregnant woman as well $(12,22,24,25)$.

Regarding the main sources of information on the negative effects of smoking in pregnancy, only $2.6 \%(\mathrm{~N}=3)$ of pregnant smokers pointed to their obstetrician and midwife, while the vast majority of them stated they received information from the public media, internet, their family and friends. This particularly small and, thus, worrisome percentage is not in accordance with the international literature, which reports that pregnant women are generally expecting to be referred to a medical specialist for particular health problems that may arise during pregnancy (e.g., to get smoking cessation treatment) while receiving care from health professionals who are monitoring their pregnancy. In a study conducted by Aveyard et al, in 2005 (26), pregnant women stated they expected midwives to ask them about smoking and advise them on quitting in case they smoked. On the other hand, midwives reported they generally faced difficulties in how to ask women about their smoking status, how to identify those who needed consultation, and how to support them in quitting smoking. Midwives were also concerned about potentially making women feel uncomfortable and whether this would be impacting the relationship of trust that a midwife is trying to build with pregnant women (27). The need to incorporate compulsory education for midwives and obstetricians at the undergraduate level as well as their lifelong education is therefore prominent, with emphasis being put on midwives working in primary healthcare settings (28). 
Regarding the psychosocial status of pregnant women who participated in our study, $13.2 \%$ $(\mathrm{N}=15)$ of them reported having an old or recent history of depression and $14.9 \%(\mathrm{~N}=17)$ an old or recent history of domestic violence. There is an observed link between smoking and depression in several studies. However, the mechanism that connects them is not fully understood (29). The mechanism of smokers' behavior is complex, and psychological dependence enhances the correlation of positive emotions with smoking. Also, smoking during pregnancy is inextricably linked to the presence of either social or economic problems or even mental illness. Achieving smoking cessation in these groups of pregnant women is particularly difficult, the rate of successful attempts being as low as $6 \%$ (12). Finally, chronic exposure to tobacco smoke is found to adversely affect the mood of women due to alterations in the neurotransmitter pathways, which in turn could lead to the development of several psychological conditions (29).

\section{Strengths and limitations}

Our study has the following strengths. First, to our knowledge, it is the first study in Greece with a sample consisting only of pregnant smokers who could not manage to quit smoking. By using a questionnaire with several questions on issues that have not been raised or highlighted so far in any Greek study regarding the characteristics of this population, we managed to investigate the obstacles and special issues of this population in order to highlight their background conditions and to draw conclusions about the extent of the issue of smoking during pregnancy. Important risk factors that affect the maternal smoking status, such as mental disorders and level of nicotine addiction, partner's smoking status and exposure to second hand smoke were recorded. This data has provided a more accurate record of the characteristics of maternal smoking in pregnancy. Moreover, the results of our study indicate the ineffectiveness of strategies used so far, which emphasizes the necessity for adopting widely improved public health policies in order to more effectively tackle the problem of pregnant non-quitters.

Regardless, this study has also several limitations which should be considered. Firstly, maternal smoking status was assessed on the basis of self-report and without further clinical assessment, and therefore, our results could potentially be affected by pregnant smokers who might have concealed their true smoking status. According to other relevant self-report studies, without measuring nicotine metabolites such as urinary cotinine, a considerable proportion of pregnant smokers - 25\% in Shipton et al's study (30) and 10\%-17.2\% in Tong et al's study (31) falsely declare that they have quitted smoking. This should be taken into account in future studies, so that researchers should not rely solely on women's self-report of their smoking status but should also control and identify pregnant smokers either by measuring $\mathrm{CO}$ emissions or using a biochemical indicator such as urinary cotinine.

Secondly, data regarding the use of e-cigarettes and other electronic nicotine delivery systems (ENDS) were not recorded. However, e-cigarette and ENDS contain several harmful substances, and chemical compounds vary between different brands. Also, numerous experimental studies in animals suggest that nicotine in ENDS alters DNA methylation, induces birth defects, reduces birth weight and affects the development of their offspring's heart and lungs. Therefore, these products are not safe to use during pregnancy, just as regular tobacco products are not safe either. So far, there is limited research on the use of ENDS during pregnancy. A cross-sectional analysis (32) as well as a systematic analysis and meta-analysis (33) highlight the risks of having an increasing number of e-cigarette users in pregnancy and the consequent need to identify and inform pregnant women who are either ENDS users only or dual users (ENDS and cigarette) about the harmful effects of these products. $\square$

\section{CONCLUSIONS}

moking disease is a major health problem in Greece. The percentage of smokers is the highest in Europe and among the highest in the world. There is also a very high rate of smoking during pregnancy both in terms of active smoking and as exposure to secondhand smoke.

It was found that a large proportion of pregnant smokers continued to smoke throughout their entire pregnancy without being offered the necessary specialized professional support for quitting smoking. Therefore, midwives and ob- 
stetricians should receive training in smoking cessation, which would enable them to provide counseling and psychosocial intervention to all pregnant women who either continue to smoke or have recently stopped smoking. Furthermore, as part of their training, they should also be instructed to refer pregnant smokers to smoking cessation clinics, where they could receive more holistic smoking related interventions.

Smoking cessation clinics in Attica have been operating for decades with high success rates (some of them the highest in Europe) in smoking cessation due to the expertise of their specially trained healthcare personnel. It was immediately noticed that pregnant women who participated in our research did not have appropriate information about services provided by these clinics, which made them believe they could not find an effective support in those settings, and consequently did not visit them. The high rates of smoking as well as the morbidity reported by pregnant smokers for their previous pregnancies may also be due to the lack of specialized smoking cessation services in maternity hospitals.

Therefore, the present study highlights the need to establish smoking cessation clinics in maternity hospitals throughout the country and to train all health professionals, mainly midwives and obstetricians, in smoking cessation. There is also a need for establishing vertical integration between maternity hospitals and the already existing smoking cessation clinics, so that the smoking cessation services already offered can become more accessible to women during the perinatal period.

The above findings are very important for a better execution of clinical practice for midwives and obstetricians working in obstetric care services during pregnancy and throughout the perinatal period and overall promote the health of women and their entire family.

Conflicts of interest: none declared.

Financial support: none declared.

Authors' contributions: $A D$ participated in study design, data collection and analysis and interpretation and manuscript drafting. AG participated in study design, data collection and analysis and interpretation.

AS and DV participated in manuscript drafting and literature revision. VK reviewed the manuscript and approved the submitted manuscript. AL contributed in the organization and supervision of the study and in the revision and final approval of the manuscript submitted.

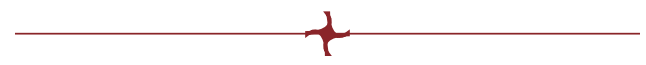

\section{$\boldsymbol{R}_{\text {EFERENCES }}$}

1. World Health Organization. Gender, Women, and the Tobacco Epidemic. World Health Organ Tech Rep Ser 2010;894(894):i-xii, 1-253. Available from: http://www.ncbi.nlm.nih.gov/ pubmed/11234459

2. Filippidis FT, Tzavara C, Dimitrakaki C, et al. Compliance with a healthy lifestyle in a representative sample of the Greek population: Preliminary results of the Hellas Health I study.

Public Health 2011;125:436-441.

Available from:

http://dx.doi.org/10.1016/j. puhe.2011.03.009

3. Diamanti A, Raftopoulos V, Lykeridou K, et al. Smoking and Pregnancy: Where are we now? An Update of the Situation in Greece. Int J Caring Sci 2019;12:79-91.

4. Vivilaki VG, Diamanti A, Tzeli M, et al. Exposure to active and passive smoking among Greek pregnant women. Tob Induc Dis 2016;14:12.

5. Koshy $\mathbf{P}$, Mackenzie M, Tappin D, et al. Smoking cessation during pregnancy: The influence of partners, family and friends on quitters and non-quitters.

Heal Soc Care Community 2010;18:500-510.

6. Tombor I, Urbán R, Berkes T, et al. Denial of smoking-related risk among pregnant smokers.

Acta Obstet Gynecol Scand 2010;89:524-530.

7. Coleman T, Thornton J, Britton J, et al.

Protocol for the Smoking, Nicotine and Pregnancy (SNAP) trial: Double-blind, placebo-randomised, controlled trial of nicotine replacement therapy in pregnancy.

BMC Health Serv Res 2007;7:1-15.

8. Orr ST, Blazer DG, Orr CA. Maternal prenatal depressive symptoms, nicotine addiction, and smoking-related knowledge, attitudes, beliefs, and behaviors.

Matern Child Health J 2012;16:973-978.

9. Howard LM, Bekele D, Rowe M, et al. Smoking cessation in pregnant women with mental disorders: A cohort and nested qualitative study. BJOG An Int J Obstet Gynaecol 2013;120:362-3670.

10. De Wilde K, Tency I, Steckel S, et al. Which role do midwives and gynecologists have in smoking cessation in pregnant women? A study in Flanders, Belgium. Sex Reprod Healthc. 2015;6:66-73. Available from: http://dx.doi.org/10.1016/j. srhc.2014.12.002

11. Holbrook BD. The effects of nicotine on human fetal development. Birth Defects Res Part C. Embryo Today Rev 
2016;108:181-192.

12. Britton GR, Collier R, McKitrick S, et al. The Experiences of Pregnant Smokers and Their Providers. Am J Nurs 2017;117:24-34.

13. Soediono B. Fagerstrom Test for Nicotine Dependence. J Chem Inf Model 1989;53:160.

14. Stergiadi E. Smoking during pregnancy. Dissertation. Hellenic open University, 2018.

15. Nunnally J, Bernstein I. Phycometric Theory, $3^{\text {rd }}$ edition, New York:McGraw-Hill, 1994.

16. Linares Scott TJ, Heil SH, Higgins ST, et al. Depressive symptoms predict smoking status among pregnant women. Addict Behav 2009;34:705-708.

Available from: http://dx.doi.org/10.1016/j. addbeh.2009.04.003

17. Papadakis S, Vyzikidou V, Vivilaki V, et al. A pilot study of the Tobacco Treatment Guidelines for High-Risk Groups (TOB-G) for pregnant and postpartum women.

Eur J Midwifery 2018;2:4-9.

18. Diamanti A, Papadakis $S$ Schoretsaniti S, et al. Smoking cessation in pregnancy: An update for maternity care practitioners. Tob Induc Dis 2019;17:57.

19. Wisborg K, Henriksen, TB, Hedegaard $\mathbf{M}$, et al. Smoking during pregnancy and preterm birth.

An Int J Obstet Gynaecol 1996;103:800-805. doi: 10.1111/j.1471-0528.1996.tb09877.x.

20. Hyland A, Piazza KM, Hovey KM, et al. Associations of lifetime active and passive smoking with spontaneous abortion, stillbirth and tubal ectopic pregnancy: a cross-sectional analysis of historical data from the Women's Health Initiative.

Tob Contro 2015;24:328-335

21. Kline J, Stein ZA, Susser M, et al. Smoking: A Risk Factor for Spontaneous Abortion.

N Engl J Med 1997;793-796.

22. Leonardi-Bee J, Britton J, Venn A. Secondhand Smoke and Adverse Fetal Outcomes in Nonsmoking Pregnant Women: A Meta-analysis.

Pediatrics 2011;127:734-741.

Available from:

http://pediatrics.aappublications.org/cgi/ doi/10.1542/peds.2010-3041

23. Haslam C, Draper ES, Goyder E. The pregnant smoker: a preliminary investigation of the social and psychological influences. J Public Health Med 1997;19:187-192.

24. Lai $Y$, Hsu T, Lan $K$, et al. Taiwanese Journal of Obstetrics \& Gynecology Asymptomatic pyuria in pregnant women during the first trimester is associated with an increased risk of adverse obstetrical outcomes. Taiwan J Obstet Gynecol 2017;56:192-195. Available from:

http://dx.doi.org/10.1016/j. tjog.2016.04.040

25. El-Mohandes AAE, Kiely M, Blake SM, et al. An intervention to reduce environmental tobacco smoke exposure improves pregnancy outcomes. Pediatrics 2010;125:721-728.

26. Aveyard P, West R. Managing smoking cessation. BMJ 2007;335:37-41.

Available from: http://www.bmj.com/cgi/doi/10.1136/ bmj.39252.591806.47

27. McLeod D, Pullon S, Benn C, et al. Can support and education for smoking cessation and reduction be provided effectively by midwives within primary maternity care?

Midwifery 2004;20:37-50.

28. Oude Wesselink SF, Lingsma HF, Robben PBM, et al. Provision and effect of quit-smoking counselling by primary care midwives.

Midwifery 2015;31:986-992.

29. Lewis SJ, Araya R, Smith GD, et al. Smoking is associated with, but does not cause, depressed mood in pregnancy - a mendelian randomization study. PLoS One 2011;6:2-6.

30. Shipton D, Tappin DM, Vadiveloo T, et al. Reliability of self reported smoking status by pregnant women for estimating smoking prevalence: A retrospective, cross sectional study. BMJ 2009;339:1241.

31. Tong VT, England LJ, Malarcher A, et al. Clinicians' awareness of the Affordable Care Act mandate to provide comprehensive tobacco cessation treatment for pregnant women covered by Medicaid.

Prev Med Reports 2015;2:686-688.

Available from: http://dx.doi.org/10.1016/j. pmedr.2015.08.013

32. Hawkins SS, Wylie BJ, Hacker MR. Use of ENDS and Cigarettes During Pregnancy. Am J Prev Med 2020;58:122-128.

33. Cardenas VM, Fischbach LA, Chowdhury P. The use of electronic nicotine delivery systems during pregnancy and the reproductive outcomes: A systematic review of the literature.

Tob Induc Dis 2019;17:1-8. 